\title{
Short Communication: Detection of Quantitative Trait Loci Influencing Somatic Cell Score in Spanish Churra Sheep
}

\author{
B. Gutiérrez-Gil, M. F. El-Zarei, Y. Bayón, L. Álvarez, L. F. de la Fuente, F. San Primitivo, and J. J. Arranz ${ }^{1}$ \\ Departamento de Producción Animal, Facultad de Veterinaria, Universidad de León, 24071, León, Spain
}

\section{ABSTRACT}

Eleven half-sib ovine families, including 1,421 Spanish Churra ewes, were analyzed for 181 microsatellite markers spanning the entire autosomic ovine genome. Using a multimarker regression method, a daughter experimental design was used to identify putative quantitative trait loci (QTL) affecting the somatic cell score (SCS). Chromosome-wise significance thresholds were set empirically by permuting the phenotypic data. Marker order and genetic distances of the autosomic linkage map built for this commercial population were in accordance with the published ovine linkage map. An across-family association analysis revealed a region on chromosome 20 suggestive of evidence for a QTL. Segregation of the QTL into 2 families was inferred from the within-family analysis, and differences in the position of the suggested QTL were found between the 2 half-sib groups. This could be the result of incomplete information associated with the markers for the significant families. The location of the major histocompatibility complex in proximity to the across-family effect suggests this region may harbor a segregating QTL for the SCS in the Churra population. Studies in dairy cattle examining the SCS have reported linkage associations on corresponding bovine orthologous regions, supporting the validity of our findings.

Key words: Churra dairy sheep, quantitative trait loci, somatic cell score

Classically, dairy sheep production systems have considered milk yield as the major selection criterion. Currently, as a result of consumers' changing demands, dairy sheep improvement must include other traits, such as milk composition, lower production costs, and enhanced quality and sanitary safety of products. Breeding programs for this species will have to involve other traits related to milkability, longevity, and disease resistance.

Received May 24, 2006.

Accepted August 9, 2006.

${ }^{1}$ Corresponding author: jjarranz@unileon.es
Mastitis is becoming a major health problem in dairy ewes. It is linked to contaminants in milk (pathogens or antibiotics), and is mainly reflected by decreased milk production and increased involuntary culling. Clinical mastitis affects approximately 5\% of sheep (Bergonier et al., 2003), compared with 20 to $40 \%$ of dairy cattle lactations (Heringstad et al., 2000). In Spanish Churra sheep, its occurrence has been estimated at $0.4 \%$ (Ariznabarreta et al., 2002), whereas the prevalence of nonsymptomatic and chronic infection has been estimated at between 16 and $35 \%$. The SCC has been described as a good indicator of subclinical infection, although breed-specific thresholds have been advised (Ariznabarreta et al., 2002). Selection for mastitis resistance in dairy sheep could focus mainly on selection against subclinical mastitis using the SCS, the logarithmic transformation of the SCC (Rupp et al., 2003a), because information exists on genetic parameters of the SCS in dairy sheep with heritability estimates ranging between 0.06 and 0.18 (Othmane et al., 2002; Rupp et al., 2003a; Legarra and Ugarte, 2005).

Efforts have recently been made to locate genes affecting economically important traits in livestock. In cattle, an increasing number of genome scans for QTL affecting udder health traits have been reported (Heyen et al., 1999). In contrast, only preliminary results of complete genome screens in sheep have been presented to date (El-Zarei et al., 2002; Rupp et al., 2003b).

In the present study, a whole-genome scan using a medium-density marker map was applied to the Spanish Churra sheep population to detect QTL for the SCS. This research made use of a daughter design involving a commercial population of 1,421 ewes belonging to 11 half-sib families distributed among 17 flocks. The average number of daughters per ram was 129 , with a range from 60 to 261. All animals considered in the study were conceived via $\mathrm{AI}$ and belonged to the selection nucleus of the National Association of Spanish Churra Breeders (ANCHE).

Deoxyribonucleic acid was extracted from blood and semen, and a total of 181 microsatellite markers distributed throughout the autosomal ovine genome were analyzed for the entire population. The initial choice of markers from published linkage maps was based on 
their position, size, and informativeness. Linkage maps were established using the CRIMAP program, version 2.4 (Green et al., 1990).

Test-day SCS records were provided by official milking records of ANCHE. The average test-day SCS (base 10 logarithmic transformation) for the whole population was 5.36 and mean values per family varied between 5.14 (family 2) and 5.56 (family 10). Response variables used in the QTL analysis were the yield deviations, estimated from the phenotypic data corrected for environmental effects (Vanraden and Wiggans, 1991) according to the statistical model described in detail by Othmane et al. (2002). Somatic cell score phenotypic measurements were corrected for the fixed effect of flock test date, the fixed effect of stage of lactation, the fixed effect of lambing age, and the fixed effect of lambing type.

The statistical power of the experiment was estimated according to Weller et al. (1990). The HSQM software (Coppieters et al., 1998), which applies the multimarker regression method described by Knott et al. (1996), was used for the QTL analysis. Chromosomewise significance thresholds were calculated by applying 10,000-permutation tests. The information content (IC) along the marker map was measured as indicated by Coppieters et al. (1998).

Marker order and genetic distances were in close agreement with the active version (version 4.5) of the third-generation linkage map of sheep (January 2006; http://rubens.its.unimelb.edu.au/ jillm/jill.htm). No inversion in marker order was observed and average difference in relative distances between our map and the reference map was low ( $3.5 \mathrm{cM}$, Kosambi; http://rubens. its.unimelb.edu.au/ jillm/jill.htm). The linkage map obtained for the Churra population spanned 3,248.2 cM (Kosambi) with an average interval size of $17.87 \mathrm{cM}$ (Kosambi). The average IC per chromosome was 0.65 , and individual values for this parameter throughout the genome ranged from 0.41 to 0.88 .

Following the method described by Weller et al. (1990) adapted to our experimental conditions (map density and marker informativeness), the power to detect real segregating QTL in this ovine population was estimated at $54 \%$ for a QTL with 2 alleles of equal frequency, with a magnitude effect of 0.3 phenotypic standard deviations and affecting a trait with a heritability of 0.1. This was assuming a type I error rate of 0.05 and a $10 \%$ recombination frequency between the QTL and marker. The statistical power of the experiment may have been increased by including more individuals in the study, especially by increasing the number of daughters per sire (Weller et al., 1990), but the experimental design had to be adapted to the restrictions associated with the commercial population under analysis. Actually, most dairy sheep management systems involve local populations with a small number of evaluated rams and a limited number of daughters for a half-sib design.

The only evidence of a QTL was found on chromosome 20 , where the $1 \%$ chromosome-wise significance level was exceeded. Genotypic information for seven markers was used to build the linkage map of this chromosome (INRA132, DYA, BM1258, OLADRPBS, BP34, BM1905, and MCMA23). Figure 1 illustrates marker IC values obtained along the linkage map built for chromosome 20, together with the $F$-ratio curve obtained for SCS in the multimarker regression analysis involving the whole population. The average IC of the 116 $\mathrm{cM}$ (Haldane) map was $65.4 \%$. The region where this parameter was lowest (0.46) was at the telomeric part of the chromosome next to marker MCMA23, which was informative in 4 of the 11 rams analyzed. The maximum IC value (0.88) was obtained at the location of OLADRBPS. This marker, for which 10 out of the 11 sires were heterozygous, was one of the most informative microsatellites analyzed in the complete genome scan, showing 23 different alleles in the population studied. According to the across-family analysis, the most likely position (95\% confidence interval) of the QTL identified, estimated by the bootstrap procedure (Visscher et al., 1996), was a large fragment encompassing $75 \%$ of the chromosome from 35 to $116 \mathrm{cM}$ (Haldane), as shown in Figure 1. The maximum value of the $F$-test was found at $103 \mathrm{cM}$ with an associated $P$-value of 0.0047 (chromosome-wise). Because the present study was part of a whole genome scan, chromosome-wise $P$-values obtained by permutation required an additional correction for multiple testing to account for the analysis of 26 autosomes. In this context, the QTL detected in chromosome 20 only attained the category of "suggestive linkage" proposed by Lander and Kruglyak (1995). Furthermore, if this resource population is being used for locating genes underlying production traits, then the experimental-wise threshold would be more strict. However, the use of a too-stringent type I error rate results in a loss of power to detect QTL in designs with limited statistical power. If the objective of the experiment is to identify QTL that will be reconfirmed in a second study, an appropriate threshold level may be the suggestive linkage, indicated by Lander and Kruglyak, both to ensure that no QTL are missed and to confirm the real nature of these QTL in future independent studies. Moreover, the approach that was applied in our study seems to be the most suitable for most livestock populations.

Individual within-family analyses (Figure 2 ) revealed 2 families (6 and 11) with significant allelic effects for the QTL based on the tabulated $F$-values $(P<0.05$ in 


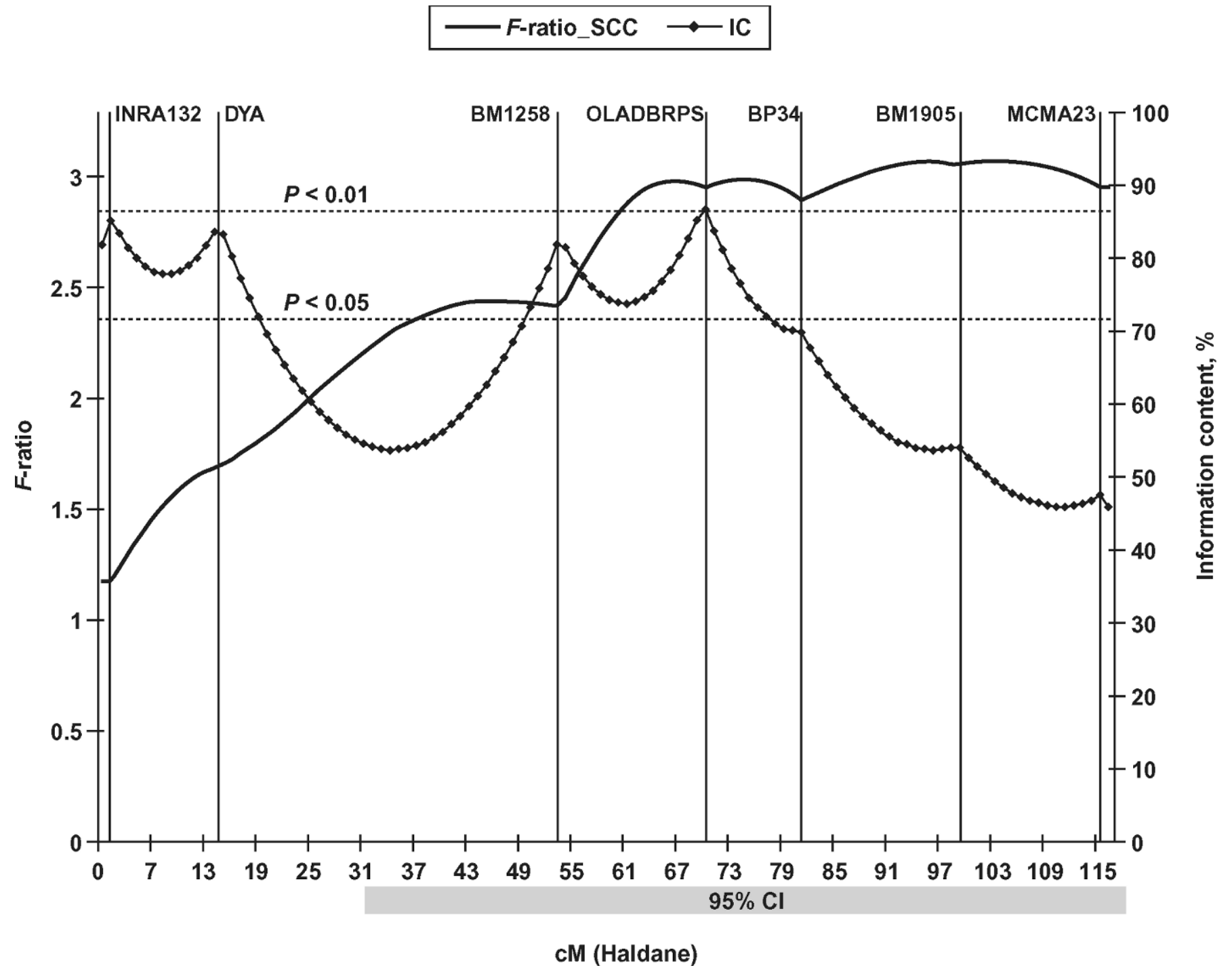

Figure 1. Chromosome 20 microsatellite map: The name of the corresponding markers is given at the top and their respective position in centimorgans (Haldane) at the bottom. The curve of black squares corresponds to the information content (expressed as a percentageright $y$-axis) obtained in the daughter design. The thick black curve corresponds to the location score obtained for somatic cell score expressed as the $F$-value statistic. The confidence interval (95\%) for QTL position obtained across 1,000 bootstrap samples is shown as a thick black horizontal bar at the bottom (CI).

the within-family analysis). Differences regarding the QTL position were observed between the 2 groups of half-sib ewes. The $F$-ratio curve reached its maximum at position $63 \mathrm{cM}$ for family 6 between markers BM1258 and OLADRBPS, and then took on a constant value, because ram 6 was not informative for the last 3 microsatellites included in the linkage map (BP34, BM1905, and MCMA23). In the case of family 11 , the $F$-test reached its maximum at $99 \mathrm{cM}$, flanked by markers BP34 and BM1905. The allele substitution effects were 0.73 and 0.56 phenotypic standard deviations for families 6 and 11, respectively. The effect of the QTL detected here was smaller than the effect estimated by
Rupp et al. (2003b) on OAR6 in Lacaune sheep, in which differences between alternative alleles of the QTL ranged from 1 to 3 genetic standard deviations.

Differences between the 2 segregating families regarding the QTL position could be explained by the distinct marker informativeness, as presented in Figure 2. Therefore, differences concerning the QTL position in 2 segregating families may be the result of the poor marker information at the telomeric end of the map. This effect was evident in family 6 , for which the $F$-ratio showed a plateau from marker OLADBRPS onward because of a lack of information in the microsatellites located in this interval. This plateau may be 


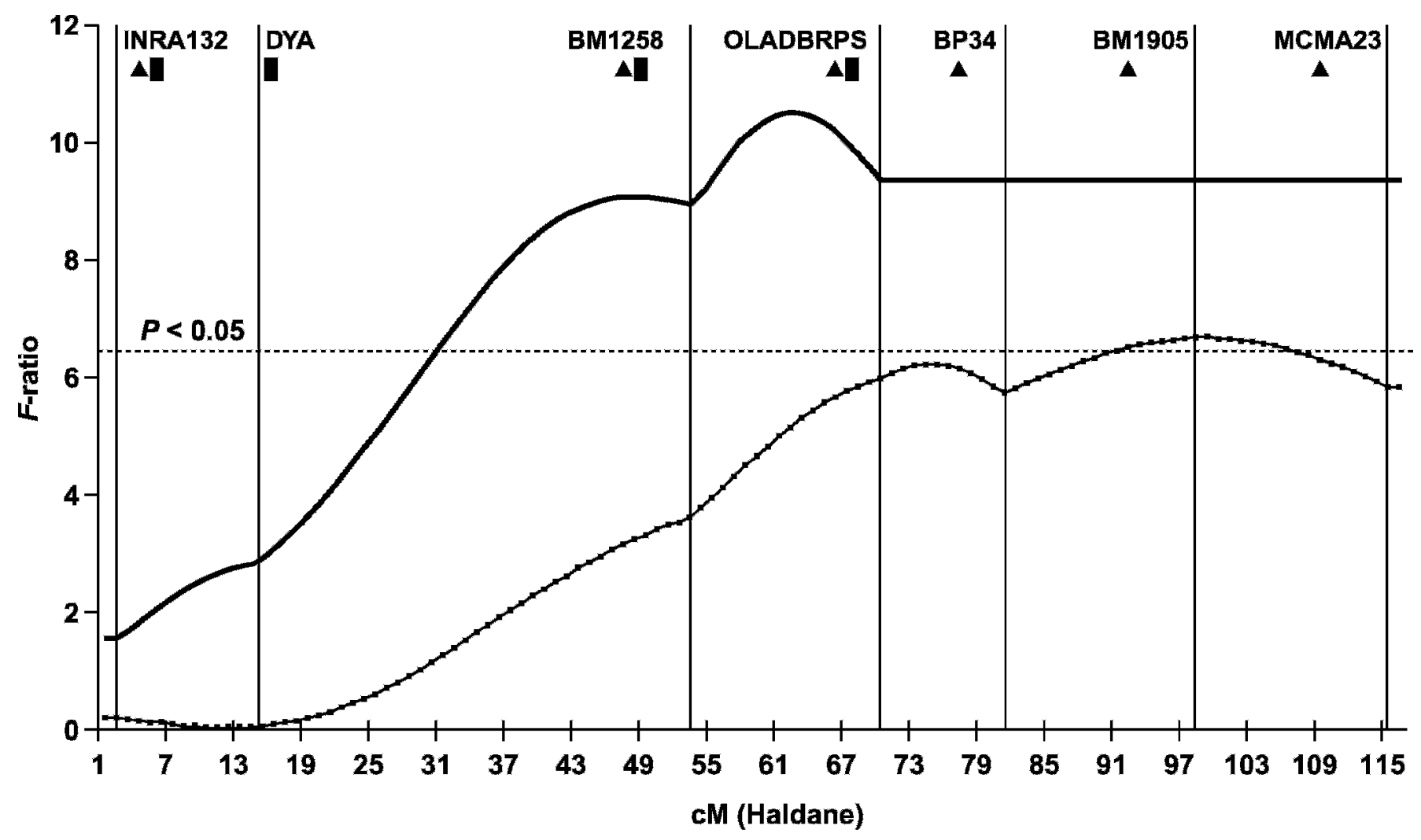

Figure 2. Test statistics curves for the analysis of SCS in families 6 (thick black curve) and 11 (line of black squares). The horizontal line shows the chromosome-wise $(P<0.05)$ threshold for SCS. Microsatellite informativity is indicated for each marker position: The presence of a black square reveals heterozygosity in family 6 , and a black triangle is used for family 11 .

the main reason for the poor resolution in the region of the QTL.

The low resolution of preliminary screenings of the entire genome to pinpoint putative QTL regions results from inherent limitations of the accuracy of the QTL position identified. Nevertheless, before a more indepth study of this region with a fine mapping approach, the location of the QTL should be determined with greater precision by increasing the marker density in the distal third of the linkage map.

No other significant QTL effects for SCS were detected in the across-family analysis, although some indications were found in other chromosomes in which individual families showed evidence of a linkage association (chromosomes 3, 8, 13, 24, and 25; results not shown). In general, a linkage association in a family was insufficient to be deemed significant in the acrossfamily analysis. Nevertheless, such suggestions of linkage should still be considered because the statistical power of our experimental design was relatively low and some genuine QTL segregating in individual families may not have been identified in the across-family analysis.
Because none of the preliminary results reported in sheep showed any evidence of QTL for the SCS on chromosome 20 (Rupp et al., 2003b), we looked for a possible correspondence with QTL reported in cattle for udder health traits. Several research groups have identified significant associations affecting the SCS on bovine chromosome 23 (Heyen et al., 1999; Ashwell et al., 2004; Holmberg and Andersson-Eklund, 2004). The closest marker to the QTL position suggested by the acrossand within-family analyses of family 6 was OLADRBPS, which is located in the major histocompatibility complex. In proximity to the bovine major histocompatibility complex, different genetic markers linked to SCS have been reported: MGTG7 (Heyen et al. 1999) and the interval BB705-BM1818 (Ashwell et al., 2004).

The substantial number of QTL reported in the syntenic region of the bovine genome affecting the SCS suggests the possibility of a conserved region among ruminants controlling part of the genetic variance of this trait, and perhaps the resistance to mastitis. Holmberg and Andersson-Eklund (2004) supported the hypothesis that some of the loci influencing the SCS may also contribute to genetic variance in clinical mastitis 
resistance, although there could be some specific QTL for each of these 2 traits. Furthermore, molecular information about markers or polymorphisms associated with the SCS could be exploited through marker- or gene-assisted selection to assist classical selection for mastitis resistance.

Our data indicate that a QTL controlling phenotypic variation of the SCC in dairy sheep maps to ovine chromosome 20, making it a candidate for fine mapping to estimate the location and the magnitude of this QTL more precisely.

\section{ACKNOWLEDGMENTS}

This work was supported by the Spanish Ministry of Education (Project 1FD97-0225) and the European Union through the project genesheepsafety (QLK52000-00656).

\section{REFERENCES}

Ariznabarreta, A., C. Gonzalo, and F. San Primitivo. 2002. Microbiological quality and somatic cell count of ewe milk with special reference to staphylococci. J. Dairy Sci. 85:1370-1375.

Ashwell, M. S., D. W. Heyen, T. S. Sonstegard, C. P. Van Tassell, Y. Da, P. M. VanRaden, M. Ron, J. I. Weller, and H. A. Lewin. 2004. Detection of quantitative trait loci affecting milk production, health, and reproductive traits in Holstein cattle. J. Dairy Sci. $87: 468-475$.

Bergonier, D., R. de Cremoux, R. Rupp, G. Lagriffoul, and X. Berthelot. 2003. Mastitis of dairy small ruminants. Vet. Res. 34:689-716.

Coppieters, W., A. Kvasz, F. Farnir, J. J. Arranz, B. Grisart, M. Mackinnon, and M. Georges. 1998. A rank-based nonparametric method for mapping quantitative trait loci in outbred half-sib pedigrees: Application to milk production in a granddaughter design. Genetics 149:1547-1555.

El-Zarei, M. F., J. J. Arranz, Y. Bayon, L. F. de la Fuente, and F. San Primitivo. 2002. Searching for chromosome 9 regions affecting somatic cell counts in Churra sheep. Page 10 in Proc. 53rd Annu.
Mtg. EAAP, El Cairo, Egypt. Wageningen Acad. Publ., Wageningen, the Netherlands.

Green, P., K. Falls, and S. Crooks. 1990. Documentation for CRIMAP, Version 2.4. Washington University School of Medicine, St. Louis, MO.

Heringstad, B., G. Klemetsdal, and J. Ruane. 2000. Selection for mastitis in dairy cattle: A review with focus on the situation of the Nordic countries. Livest. Prod. Sci. 64:95-106.

Heyen, D. W., J. I. Weller, M. Ron, M. Band, J. E. Beever, E. Feldmesser, Y. Da, G. R. Wiggans, P. M. VanRaden, and H. A. Lewin. 1999. A genome scan for QTL influencing milk production and health traits in dairy cattle. Physiol. Genomics 1:165-175.

Holmberg, M., and L. Andersson-Eklund. 2004. Quantitative trait loci affecting health traits in Swedish dairy cattle. J. Dairy Sci. 87:2653-2659.

Knott, S. A., J. M. Elsen, and C. S. Haley. 1996. Methods for multiplemarker mapping of quantitative trait loci in half-sib population. Theor. Appl. Genet. 93:71-80.

Lander, E., and L. Kruglyak. 1995. Genetic dissection of complex traits: Guidelines for interpreting and reporting linkage results. Nat. Genet. 11:241-247.

Legarra, A., and E. Ugarte. 2005. Genetic parameters of udder traits, somatic cell score, and milk yield in Latxa sheep. J. Dairy Sci. 88:2238-2245.

Othmane, M. H., L. F. de La Fuente, J. A. Carriedo, and F. San Primitivo. 2002. Heritability and genetic correlations of test day milk yield and composition, individual laboratory cheese yield, and somatic cell count for dairy ewes. J. Dairy Sci. 85:2692-2698.

Rupp, R., G. Lagriffoul, J. M. Astruc, and F. Barillet. 2003a. Genetic parameters for milk somatic cell score and relationships with production traits in French Lacaune dairy sheep. J. Dairy Sci. 86:1476-1481.

Rupp, R., L. Schibler, E. Cribiu, Y. Amigues, M. Y. Boscher, L. Mura, T. Sechi, A. Fraghi, S. Casu, F. Barillet, and A. Carta. 2003b. Evidence of chromosomal regions controlling somatic cell counts in dairy sheep from two QTL detection projects. Communication no. 2-32 in Proc. Int. Workshop on Major Genes and QTL in Sheep and Goats. INRA, Toulouse, France.

Vanraden, P. M., and G. R. Wiggans. 1991. Derivation, calculation, and use of national animal model information. J. Dairy Sci. 74:2737-2746.

Visscher, P. M., R. Thompson, and C. S. Haley. 1996. Confidence intervals in QTL mapping by bootstrapping. Genetics 143:1013-1020.

Weller, J. I., Y. Kashi, and M. Soller. 1990. Power of daughter and granddaughter designs for determining linkage between marker loci and quantitative trait loci in diary cattle. J. Dairy Sci. 73:2525-2537. 